outcome measure in systemic sclerosis. J Rheumatol. 2014;41(11):21862192.

[3] Sebastiani M, Manfredi A, Colaci M,et al. Capillaroscopic skin ulcer risk index: a new prognostic tool for digital skin ulcer development in systemic sclerosis patients. Arthritis Rheum 2009; 61: 688-694

[4] Ruaro B, Sulli A, Smith V, et al. Advances in nailfold capillaroscopic analysis in systemic sclerosis. JSRD 2018; 3 : $122-131$

Disclosure of Interests: None declared

DOI: 10.1136/annrheumdis-2019-eular.2627

\section{AB0676 1 BODY COMPOSITION IN MYOSITIS PATIENTS AND THE ASSOCIATION WITH DISEASE SPECIFIC FEATURES, PHYSICAL ACTIVITY AND PLASMA LEVELS OF INFLAMMATORY CYTOKINES}

Sabina Oreska ${ }^{1,2}$, Maja Špiritović ${ }^{3},{\text { Petr } \text { Česák }^{3} \text {, Ondrej Marecek }}^{3}$,

Hana Štorkánová ${ }^{1,2}$, Hana Smucrova ${ }^{1}$, Barbora Heřmánková ${ }^{3}$,

Kateřina Kubinova ${ }^{1,2}$, Martin Klein $^{1,2}$, Lucia Vernerová1, ${ }^{1,}$, Olga Růžičková ${ }^{1,2}$, Karel Pavelka ${ }^{1,2}$, Ladislav Šenolt ${ }^{1,2}$, Heřman Mann ${ }^{1,2}$, Jiří Vencovsky $y^{1,2}$, Michal Tomčík ${ }^{1,2} .{ }^{1}$ Institute of Rheumatology, Prague, Czech Republic; ${ }^{2} 1$ st Faculty of Medicine, Charles University, Department of Rheumatology, Prague, Czech Republic; ${ }^{3}$ Faculty of Physical Education and Sport, Charles University, Department of Physiotherapy, Prague, Czech Republic

Background: Skeletal muscle, pulmonary, and articular involvement in idiopathic inflammatory myopathies (IIM) limit the mobility/self-sufficiency of patients, and can have a negative impact on body composition.

Objectives: To assess body composition and physical activity of IIM patients and healthy controls $(\mathrm{HC})$ and the association with selected inflammatory cytokines in IIM.

Methods: 54 patients with IIM (45 females; mean age 57.7; disease duration 5.8 years; PM, (22)/DM, (25)/IMNM, (7)) and 54 age-/sexmatched HC (45 females, mean age 57.7) without rheumatic/tumor diseases were included. PM/DM patients fulfilled Bohan/Peter criteria for PM/ DM. We assessed body composition (densitometry: iDXA Lunar, bioelectric impedance: BIA2000-M), physical activity (Human Activity Profile, HAP questionnaire), disease activity (MITAX and MYOACT activity score), muscle involvement (manual muscle test, MMT-8 and functional index, FI2) and plasma levels of 27 cytokines (commercial multiplex ELISA kit, Bio-Rad Laboratories). Data are presented as mean $\pm S D$.

Results: Compared to $\mathrm{HC}$, patients with IIM had a trend towards significantly increased body fat $\%(B F \%)$ as assessed by iDXA $(39.9 \pm 7.1$ vs. $42.4 \pm 7.1 \%, p=0.077$ ), but significantly decreased lean body mass (LBM) as assessed both by iDXA $(45.6 \pm 8.1$ vs. $40.6 \pm 7.2 \mathrm{~kg}, \mathrm{p}=0.001)$ and $\mathrm{BIA}$ $(52.6 \pm 8.8$ vs. $48.7 \pm 9.0 \mathrm{~kg}, \mathrm{p}=0.023)$, and increased extracellular mass/ body cell mass (ECM/BCM) ratio $(1.06 \pm 0.15$ vs. $1.44 \pm 0.42, \quad \mathrm{p}<0.001)$, reflecting deteriorated nutritional status and worse muscle predispositions for physical activity. Compared to $\mathrm{HC}$, IIM patients had significantly lower bone mineral density (BMD: $1.2 \pm 0.1$ vs. $1.1 \pm 0.1 \mathrm{~g} / \mathrm{cm}^{2}, \mathrm{p}<0.001$ ). Disease duration negatively correlated with BMD ( $r=-0.392, p=0.004)$ and LBM-BIA $(r=-0.272, \quad p=0.047)$. Disease activity assessed by both MITAX and MYOACT positively correlated with LBM-BIA (MITAX: $r=0.294, p=0.031$; MYOACT: $r=0.335, p=0.013$ ) and LBM-DXA (MITAX: $r=0.341, p=0.012$; MYOACT: $r=0.368, p=0.007$ ), similarly as with basal metabolic rate (BMR; MITAX: $r=0.336, p=0.014$; MYOACT: $r=0.351, p=0.010$ ), and fat free mass (FFM; MITAX: $r=0.338, p=0.014$; MYOACT: $r=0.356, p=0.009$ ). CRP was positively associated with BF\% assessed both by DEXA ( $r=0.276$, $p=0.035)$ and BIA $(r=0.306, p=0.025)$. Higher $B F \%-D E X A$ was associated with worse physical endurance $(F \mid 2$ : $r=-0.311, p=0.026)$ and worse ability to perform physical activity (HAP: $r=-0.292, p=0.032$ ). MMT-8 score negatively correlated with $\mathrm{ECM} / \mathrm{BCM}$ ratio $(r=-0.385, \mathrm{p}=0.006)$. Plasma levels of IL-1ra positively correlated with body mass index (BMI, $r=0.359$, $p=0.009), \quad B F \% \quad(r=0.363, \quad p=0.009)$, and visceral fat $(V F, \quad r=0.409$, $\mathrm{p}=0.003$ ). Plasma levels of $\mathrm{MCP}-1$ positively correlated with $\mathrm{ECM} / \mathrm{BCM}$ ratio $(r=0.387, p=0.005)$. Increased plasma levels of $\mathrm{IL}-10$ were associated with decreased LBM ( $r=-0.473, p=0.014)$.

Conclusion: Compared to healthy age-/sex-matched individuals we found significant negative changes in body composition of our IIM patients, which are associated with their disease activity and duration, inflammatory status, skeletal muscle involvement, and physical activity. Plasma levels of several inflammatory cytokines were associated with alterations of body composition in IIM patients and highlight the potential role of inflammatory status on impaired body composition during the course of IIM.

Acknowledgement: Supported byAZV NV18-01-00161A, MHCR 023728 and GAUK 312218
Disclosure of Interests: Sabina Oreska: None declared, Maja Špiritović: None declared, Petr Česák: None declared, Ondrej Marecek: None declared, Hana Štorkánová: None declared, Hana Smucrova: None declared, Barbora Heřmánková: None declared, Kateřina Kubinova: None declared, Martin Klein: None declared, Lucia Vernerová: None declared Olga Růžičková: None declared, Karel Pavelka: None declared, Ladislav Šenolt Grant/research support from: AbbVie, Consultant for: AbbVie, Bris tol-Myers Squibb, Celgene Corporation, Merck Sharp and Dohme, Novar tis, Pfizer, Roche, UCB, Amgen, Takeda, Speakers bureau: AbbVie Amgen, Bristol-Myers Squibb, Celgene Corporation, Eli Lilly, Merck Sharp and Dohme, Novartis, Pfizer, Roche, UCB, Heřman Mann Consultant for: Pfizer, Eli Lilly, Sanofi, Speakers bureau: AbbVie, Roche, Pfizer, MSD, Eli Lilly, Sanofi, Jiří Vencovský Consultant for: Samsung, Speakers bureau: AbbVie, Novartis, Pfizer, Sanofi, Eli Lilly, Biogen, UCB, MSD Werfen, Roche, Michal Tomčík: None declared DOI: 10.1136/annrheumdis-2019-eular.4126

\section{AB0677 TREATMENT OF IDIOPATHIC INFLAMMATORY MYOPATHIES - A SINGLE CENTRE EXPERIENCE}

Jaka Ostrovrsnik ${ }^{1}$, Ziga Rotar ${ }^{1}$, Matija Tomsic ${ }^{1,2}$, Alojzija Hocevar ${ }^{1,2} .{ }^{1}$ University Medical Center, Ljubljana, Department of Rheumatology, Ljubljana, Slovenia; ${ }^{2}$ University of Ljubljana, Faculty of Medicine, Ljubljana, Slovenia

Background: There is no consensus or recommendations for the treatment of idiopathic inflammatory myopathies (IIM).

Objectives: We explored how we treated incipient IIM patients in our secondary/tertiary rheumatology centre.

Methods: We retrospectively included cases with IIM diagnosed between January 2010 and June 2018, who were followed at least 6 months. The remission inducing treatment and the treatment at the last follow-up were recorded

Results: During the 102-month period we identified 102 IIM cases $(71.6 \%$ female, median (IQR) age 62.7 (52.2-72.1) years): $27.5 \%$ dermatomyositis, $22.5 \%$ anti-synthetase syndrome, $14.7 \%$ myositis in an overlap syndrome, $13.7 \%$ immune mediated necrotizing myopathy, $11.5 \%$ polymyositis, $6.9 \%$ cancer associated myositis, $2.9 \%$ inclusion body myositis (IBM), 1\% unspecified myositis. 94 (92.2\%) patients received glucocor ticoids (GC), 18/94 (17.6\%) as monotherapy. The remaining $81(79.4 \%)$ were treated with additional immunomodulatory agents (Table 1), most commonly methotrexate. In addition to therapy presented in Table 1, 13 $(12.7 \%)$ also received human immunoglobulins (IVIG), one (1\%) received plasma exchange therapy.

Of the $8(7.8 \%)$ cases who were not treated with GC 3 received metho trexate, 1 rituximab, and 4 no additional treatment (1 paraneoplastic polymyositis received chemotherapy, 2 IBM, 1 mild polymyositis in elderly multimorbid patient).

In the first 6 months following diagnosis, 11 patients died ( 3 due to infection, 2 as a consequence of IIM, 1 due to haemorrhagic shock, 5 of unknown causes), and 5 were lost to follow-up. The remaining 86 patients were followed for a median (IQR) 37.7 (20.2-62.6) months. At last follow-up $49(57 \%)$ patients were still receiving GC, 8 (9.3\%) in monotherapy. $9(10.5 \%)$ cases were off GC and other maintenance treatment. Maintenance treatment at last follow-up is presented in Table 2. Treatment was changed in $13(15.1 \%)$ patients (due to progression of pulmonary involvement in 3 , active myositis in 4 , pulmonary involvement progression and active myositis in 1 and due to intolerance to medication in 6 cases). In addition to therapy presented in Table 2, 2 (2.3\%) patients received IVIG (1 concurrently with rituximab and mycophenolic acid due to recalcitrant anti-synthetase syndrome and 1 due to IBM complicated with dysphagia).

Table 1. Induction treatment of idiopathic inflammatory myopathy

\begin{tabular}{lc}
\hline Type of treatment & $\mathbf{N}(\%)$ \\
\hline Cyclophosphamide; median dose (range) & $23(22.5) ; 6(2-12) \mathrm{g}$ \\
Methotrexate & $43(42.2)$ \\
monotherapy & $30(69.8)$ \\
+ cyclosporine A & $8(18.6)$ \\
+ cyclosporine A and rituximab & $4(9.3)$ \\
+ chloroquine & $1(2.3)$ \\
Rituximab monotherapy & $4(3.9)$ \\
Azathioprine & $3(2.9)$ \\
Mycophenolic acid & $3(2.9)$ \\
Cyclosporine A monotherapy & $1(1.0)$ \\
\hline
\end{tabular}

